factors in this respect in this survey were patients' views and medico-legal aspects; most respondents considered these important, but many felt that they did not know enough. Similarly, doctors thought they had a poorer understanding of the relatives' views than did nurses, and the junior doctors also considered that they were less aware of the views of other members of the multidisciplinary team than other professionals. These findings could reflect either a real lack of information or poor communication, and require further study.

Freedom from pain was identified as an important aspect of quality of life by many respondents; however, a substantial minority of respondents were not confident in managing the pain relief of the dying patient. Neither psychiatrists nor psychiatric nurses currently receive any special training in this aspect of what has been described as the "terminal care of psychogeriatric in-patients" (Black \& Jolley, 1990). Further education in analgesia could usefully be incorporated into psychiatric training of both professions.

\section{Acknowledgements}

We are grateful to all our colleagues who participated in the study.

\section{References}

Black, D. \& JolleY, D. (1990) Slow euthanasia? The deaths of psychogeriatric patients. British Medical Journal, 300, 1321-1323.

Hope, T. (1992) Advance directives about medical treatment. British Medical Journal, 304, 398.

La Puma, J., Orentrlicher, D. \& Moss, R. J. (1991) Advance directives on admission. Journal of the American Medical Association, 266, 402-405.

Molloy, D. W., Clarnette, R. M., Braun, E. A., Eismann, M. R. \& Sneidermann, B. (1991) Decision making in the incompetent elderly: "The daughter from California syndrome". Journal of the American Geriatrics' Society, 39, 396-399.

OPPENHEIMER, C. (1991) Ethics and the psychiatry of old age. In Psychiatry in the Elderly (eds. R. Jacoby and C. Oppenheimer). Oxford: Oxford University Press.

\title{
Survey of undergraduate teaching of old age psychiatry in the United Kingdom
}

\author{
Gabrielle M. Fatre, Senior Registrar in Psychiatry, Mental Health Unit, \\ Basildon Hospital, Basildon SS16 5NL; and CoRnelius L. E. KaTONA, Professor of \\ Psychiatry of the Elderly, Department of Psychiatry, University College London \\ School of Medicine, Wolfson Building, Middlesex Hospital, London WIN 8AA
}

Old age psychiatry has been steadily developing as a specialty in the United Kingdom. In 1978 the Royal College of Psychiatrists established a specialist section for old age psychiatry, and since October 1989 it has been formally recognised as a sub-specialty of psychiatry. In 1989 the Royal College of Physicians and the Royal College of Psychiatrists published a joint report entitled 'Care of Elderly People with Mental Illness' in which recommendations were made about both postgraduate and undergraduate training.

The recommendations concerning postgraduate training have in the main been adopted by the Joint Committee in Higher Psychiatric Training, who published a revised position statement on training in old age psychiatry in November 1989. With respect to undergraduate education the joint report commented that "there is little information as to the quality and context of students' exposure in the different medical schools". The report recommended that each medical school should have a senior academic post in old age psychiatry, and that all medical students should receive training in old age psychiatry, with consideration given to integrating teaching with that given in geriatric medicine.

\section{The study}

In this survey, we aimed to explore the current state of undergraduate teaching in the subject, to see the extent to which these recommendations are being met, and to identify differences in teaching offered by the 27 medical schools currently providing undergraduate training in old age psychiatry. 
A questionnaire was mailed to the University Departments of Psychiatry in the 27 medical schools in the United Kingdom, addressed either to a known academic in an old age psychiatry post, or to the Head of Department of Psychiatry.

\section{Findings}

Results were received from all of the schools.

\section{Academic posts}

Six departments have Professors of Old Age Psychiatry, and one department a Professor of Health Care of the Elderly, who is psychiatrist. Two other departments reported that the Professor of Psychiatry devoted a significant proportion of time to old age psychiatry research.

Ten departments have senior lecturer posts. A total of 14 filled posts were identified, eight full-time and six part-time. One department has an unfilled post. In addition, one department has six NHS consultants who are designated 'honorary lecturers'. Seven departments have lecturers in post, and three have unfilled posts. One department reported having an honorary lecturer, another a locum lecturer, and another a 'tutor/honorary senior registrar in old age psychiatry', and a lecturer in the department of the psychology of old age.

In total, 14 departments have at least one academic post in old age psychiatry, although in three cases this is a lecturer post only.

\section{Organisation of the teaching programme}

Eighteen departments reported that there was formal involvement of an old age psychiatrist in the planning of the student teaching programme in psychiatry. In 15 departments one person was considered to have overall responsibility for organising the teaching of old age psychiatry to students, this person being a senior academic in old age psychiatry in eight cases. Only five departments reported having a formal written curriculum for old age psychiatry teaching, although two departments were in the process of developing one. In ten departments all the staff involved in old age psychiatry teaching met to discuss the teaching programme.

\section{Proportion of teaching devoted to old age psychiatry}

Respondents were asked to estimate what proportion of psychiatry teaching is devoted to old age psychiatry. Eighteen estimates were given, ranging from $2.5-25 \%$, with a median of $15 \%$.

\section{Joint teaching with geriatric medicine}

One department has a joint teaching programme. In addition there are nine departments in which old age psychiatrists participate in the geriatric medicine teaching programme, and in five of these geriatricians also participate in the old age psychiatry teaching programme.

\section{Method of teaching}

In all but two departments students receive formal lectures in old age psychiatry. In 20 departments students are taught in a tutorial setting, although in six of these not all students receive the same amount of teaching.

The total number of hours of teaching students receive, either by lecture or tutorial, ranges from 1-14 hours, with a median of six hours. The amount of informal, clinically based teaching received by students also varies widely, both between and within departments, depending on whether or not students have an attachment to an old age psychiatry firm.

\section{Topics covered}

Respondents were asked which topics were covered by formal lectures or tutorials, and how much time was allocated to each, with a suggested list of topics being dementia, assessment of cognitive state, neuropathology, the ageing process, service organisation, affective disorders, paraphrenia and psychopharmacology.

Six respondents felt unable to answer this question, but of the remainder almost all replied that students were taught about dementia, assessment of cognitive state, the ageing process, affective disorders in the elderly, service organisation and paraphrenia. Only ten reported teaching on psychopharmacology, six on neuropathology and one on confusional states.

Several respondents commented that many of the subjects were covered in other parts of the psychiatry course, rather than in specific old age psychiatry teaching.

The amount of time devoted to particular subjects varied widely between departments, from ten minutes to several hours.

\section{Student attachments to old age psychiatry firms}

In seven departments all students have an attachment to an old age psychiatry firm. In three departments no attachments are offered to students. In the remainder, between $5 \%-75 \%$ of students have an attachment, varying in length between nine weeks whole-time to one week part-time.

\section{Standardised assessments}

The most widely used standardised assessment is the Mini Mental State Examination which is regularly used in 18 departments, and taught to students in 15 . The Abbreviated Mental Test Score and the CAPE information orientation scale are used regularly in 
eight departments and taught to students in five. The Middlesex Elderly Assessment of Mental State is used in four departments, although not taught to students, and the short CARE is used in three departments and taught to students in one. Other than these, a wide variety of assessments are used by individual departments, with only four reporting no use at all of standardised assessments.

\section{Comment}

In 1981 Wattis et al identified, as the only full-time academic posts in old age psychiatry in the UK, one chair (of health care of the elderly), one senior lecturer post and one lecturer post, all in the one department. By 1984, two new chairs had been created (Wattis \& Arie, 1984) and by 1989 a further one (Royal College of Physicians and Royal College of Psychiatrists, 1989). This survey identified another three chairs, and a substantial increase in the number of senior lecturer and lecturer posts, representing a considerable expansion of academic posts over the last decade, particularly in recent years. However (with 13 departments having no academic posts and three having lecturer posts only) more than half of all departments are still lacking a senior academic in old age psychiatry. Joint teaching programmes remain fairly rare, with only five departments having reciprocal involvement of old age psychiatrists and geriatricians in each other's programmes.

Although in two-thirds of departments old age psychiatrists are involved in planning the student teaching programme in psychiatry, only five have a written curriculum for old age psychiatry. Nevertheless there does seem to be an unofficial 'core curriculum' that virtually all departments subscribe to, in that much the same topics are taught everywhere, although with a great variation in the time allocated.

In 1985 Arie et al described a 'pocket portable curriculum' for the teaching of old age psychiatry. There is clearly now an opportunity for the old age psychiatry section of the College to propose a standard curriculum based on this for the teaching of old age psychiatry to medical students.

There is great variation in the amount of clinical experience in old age psychiatry received by students, with a substantial proportion of students receiving none. However, the need for clinical skills in the management of elderly people is becoming increasingly important in all but a few medical specialities, and there is a strong case for arguing that all medical students should have clinical experience in old age psychiatry, as recommended in the Joint Report. Recommendations from the College would be helpful in establishing nationally accepted guidelines as to an acceptable minimum of undergraduate clinical experience in the subject.

\section{References}

ARIE, T., Jones, R. \& SMIth, C. (1985) The educational potential of old age psychiatry services. In Recent Advances in Psychogeriatrics (ed. T. Arie). Edinburgh: Churchill-Livingston.

Royal College of Physicians \& Royal College of Psychiatrists (1989) Care of Elderly People with Mental Illness. Specialist Services and Medical Training. London: The Royal College of Physicians of London and The Royal College of Psychiatrists.

WATTIS, J. \& ARIE, T. (1984) Further developments in psychogeriatrics in Britain. British Medical Journal, 289, 778.

-, Wattis, L. \& ARE, T. (1981) Psychogeriatrics: a national survey of a new branch of psychiatry. British Medical Journal, 282, 1529-1533. 